our twins had completed a detailed survey of hair and eye colour and height and had reported that when they were children parents and teachers had had difficulty telling them apart. Such surveys are reliable for determining zygosity.

The present study indicates that caution should be exercised before accepting a single gene hypothesis for pre-eclampsia. Pre-eclampsia is not a maternal autosomal recessive condition because in recessive in heritance penetrance of the homozygote should be near $100 \%$. We cannot rule out dominant inheritance with incomplete penetrance, but the upper limit for this penetrance is about $31 \%$.
This study was supported by the University of Wales College of Medicine Research Initiative Fund.

1 Chesley LC, Cooper DW. Genetics of hypertension in pregnancy: pessible gene control of pre-eclampsia and eclampsia in the descendants of ellamptic control of pre-eclampsia and eclampsia in
women. Br f Obstet Gynaecol 1986;93:898-908.

2 Arngrimsson R, Bionsson S, Geirsson RT, Bjornsson H, Walker JJ, Snacdal G Genetic and familial predisposition to eclampsia and pre-eclampsia in defined population. Br f Obstet Gynoecol 1990;97:762-9.

3 Kasriel J, Eaves L. The zygosity of twins, further evidence of the agreement between diagnosis by blood groups and written questionnaires. $\mathcal{F}$ Biosoc Sci 1976;8:263-6.

4 Thornton JG, Sampson J. Genetics of pre-eclampsia. Lancet 1990;ii:1319-20.

5 Thompson B, Fraser $\mathrm{C}$. Some aspects of first births and the heights of twin sisters of known zygosity. In: MacGillivray I, Campbell DM, Thompson B, eds. Twinning and twins. Chichester: Wiley, 1988:253-63.

(Accepted 13. Fune 1991)

\title{
Safety of thrombolysis in association with cardiopulmonary resuscitation
}

\section{Stephen J Cross, Hai Shiang Lee, John M Rawles, Kevin Jennings}

Cardiac Department, Aberdeen Royal Infirmary, Aberdeen AB9 2ZD

Stephen J Cross, MRCP registrar

Hai Shiang Lee, MRCP, registrar

Kevin Jennings, FRCP, consultant

Department of Medicine and Therapeutics,

University of Aberdeen, Aberdeen

John M Rawles, FRCP, consultant

Correspondence to:

Dr Cross.

BMF 1991;303:1242
Thrombolysis is now standard first line treatment for acute myocardial infarction: infarct size is decreased and mortality reduced.' Owing to the temporary systemic fibrinolytic state induced by this treatment thrombolytic agents are not recommended after prolonged or traumatic cardiopulmonary resuscitation. ${ }^{3+}$ Therefore patients who would potentially benefit from thrombolysis may be denied it if they have an arrest before or shortly after admission to hospital and require more than cardioversion for resuscitation. For example, patients with primary ventricular fibrillation after myocardial infarction have larger infarcts than those who do not ${ }^{5}$ and might therefore benefit from thrombolytic treatment.

We looked for bleeding complications in a consecutive series of patients presenting with acute myocardial infarction who had a cardiac arrest before or shortly after receiving thrombolysis.

\section{Patients, methods, and results}

Thirty nine patients presented to Aberdeen Royal Infirmary during 1990 with acute myocardial infarction treated by thrombolysis and had an early (within 24 hours) cardiac arrest not associated with cardiogenic shock. Myocardial infarction was diagnosed according to standard World Health Organisation criteria in those who survived and from the history and electrocardiogram in those who died.

The patients were divided into three groups (table). Patients in group I had a cardiac arrest before receiving thrombolysis; four of them had chest compression with cardioversion and the rest cardioversion alone. There were no bleeding complications. One patient died a

Characteristics of three groups of patients who presented with acute myocardial infarction and had cardiac arrest before or shortly after thrombolysi

\begin{tabular}{|c|c|c|c|}
\hline & \multirow{2}{*}{$\begin{array}{c}\text { Cardiac arrest } \\
\text { before thrombolysis }\end{array}$} & \multicolumn{2}{|c|}{ Cardiac arrest after thrombolysis } \\
\hline & & Resuscitation unsuccessful & Resuscitation successful \\
\hline No of patients & 10 & 18 & 11 \\
\hline Mean age (years) & $64 \cdot 8$ & $69 \cdot 1$ & $62 \cdot 7$ \\
\hline Age range (years) & $51-79$ & $56-79$ & $47-73$ \\
\hline $\operatorname{Sex}(M / F)$ & $6 / 4$ & $11 / 7$ & $7 / 4$ \\
\hline \multicolumn{4}{|l|}{ Diagnosis (No of patients): } \\
\hline Electromechanical dissociation & & 7 & \\
\hline Asystole & 1 & 6 & 2 \\
\hline Ventricular fibrillation & 6 & 4 & 7 \\
\hline Ventricular tachycardia & 2 & & 1 \\
\hline Unknown & 1 & 1 & 1 \\
\hline
\end{tabular}

week later; postmortem examination showed extensive myocardial infarction with biventricular failure.

Patients in groups II and III had a cardiac arrest within 24 hours after receiving thrombolysis. Those in group II could not be resuscitated despite chest compression in all cases, and cardioversion when appropriate. No bleeding complications were reported at the time. Patients in group III were successfully resuscitated. Chest compression was performed in two patients, the others having cardioversion alone. The only bleeding complication was a chest wall haematoma after a precordial blow in a patient who did not have chest compression; the haematoma resolved completely.

When group II and group III were compared, group II had significantly more arrests secondary to electromechanical dissociation and asystole $(\mathrm{p}<0.05)$ and significantly fewer from ventricular fibrillation and tachycardia $(\mathrm{p}<0.01)\left(\chi^{2}\right.$ tests $)$.

\section{Comment}

Although thrombolysis may be associated with haemorrhagic complications, we found no clinically significant bleeding complications in patients receiving such treatment either before or after cardiopulmonary resuscitation. All but one of the patients who received thrombolysis after resuscitation (group I) survived to leave hospital. Four of them had had chest compression without any adverse effects, and postmortem examination of the only patient who died in this group showed no evidence of internal bleeding. The only bleeding complication in the series, in a patient who received thrombolysis before resuscitation, was a chest wal haematoma from a precordial blow, and this completely resolved.

Cardiac rupture may be a complication of thrombolysis and may explain the high incidence of apparent rupture in our series. Most of our patients had a cardiac arrest while their heart rhythms were being monitored; the hearts of those with asystole and electromechanical dissociation (and presumed rupture) would be expected to have ruptured before the start of resuscitation

Although our study was small, the results suggest that cardiopulmonary resuscitation is not a clear contraindication to thrombolysis.

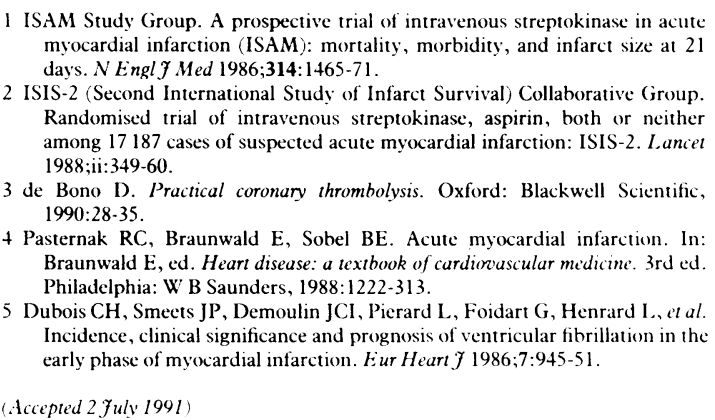
myocardial infarction (ISAM): mortality, morbidity, and infarct size at days. N Engl F Med 1986;314:1465-71.

2 ISIS-2 (Second International Study of Infarct Survival) Collaborative (jroup. Randomised trial of intravenous streptokinase, aspirin, both or neither among 17187 cases of suspected acute myocardial infarction: ISIS-2. Lancet 1988;ii:349-60

de Bono D. Practical coronary thrombolysis. Oxford: Blackwell Scientific, 1990:28-35

4 Pasternak RC, Braunwald E, Sobel BE. Acute myocardial infarction. In: Braunwald $\mathrm{E}$, ed. Heart disease: a textbook of cardiovascular medicine. 3rd ed. Philadelphia: W B Saunders, 1988:1222-313.

5 Dubois $\mathrm{CH}$, Smects JP, Demoulin JCI, Pierard L, Foidart G, Henrard L, al. Incidence, clinical significance and prognosis of ventricular fibrilbtion in the early phase of myocardial infarction. Eur Heart f 1986;7:945-51. 